\title{
Occupational therapists' views on core competencies that graduates need to work in the field of neurology in a South African context
}

\author{
L Jacobs-Nzuzi Khuabi, PhD (OT), MPH (Health Economics), BSc (OT); \\ J Bester, B OT, BSc Hons (Epidemiology and Biostatistics), M Phil (Higher Education), PG Dip (Program Monitoring and Evaluation)
}

Division of Occupational Therapy, Department of Health and Rehabilitation Sciences, Faculty of Medicine and Health Sciences, Stellenbosch University, Cape Town, South Africa

Corresponding author: L Jacobs-Nzuzi Khuabi (leeann@sun.ac.za)

\begin{abstract}
Background. The burden of neurologically related conditions in South Africa (SA) necessitates that undergraduate occupational therapy education and training provide students with core competencies to deliver comprehensive, effective client-centred interventions. Given developments in the practice of neurology and changes in policy, funding and infrastructure, it is essential that training remains relevant and responsive to the needs of individuals and their context. Occupational therapists should be in touch with the local context and its challenges and consider the practicalities of the suggested interventions. Objectives. To explore occupational therapists' perspectives on the knowledge, skills and attitudes that graduates need to work in the field of neurology. Methods. An explorative qualitative study consisting of semi-structured interviews was conducted with 10 occupational therapists in Western Cape Province, SA. Data were analysed using inductive analysis.

Results. Four themes emerged from the findings, including foundational knowledge and skills, intra- and interpersonal attitudes, suggestions to consider when revising a neurology curriculum and resource constraints.

Conclusions. This study highlighted that, in addition to neurology-specific skills, graduates also require core generic knowledge, skills and attitudes that address the evolving needs of society. These competencies are further necessary to allow graduates to work within the constraints of the health and educational systems.
\end{abstract}

Afr J Health Professions Educ 2020;12(1):36-40. https://doi.org/10.7196/AJHPE.2020.v12i1.1021

The South African (SA) population is burdened by a prevalence of neurological conditions, such as congenital, acquired and progressive disorders. ${ }^{[1]}$ Given the effect of neurological conditions on a person's quality of life, these form a sizeable proportion of an occupational therapist's workload in school and healthcare settings. ${ }^{[2]}$ The assessment and treatment of persons with neurological conditions are included in undergraduate occupational therapy courses to prepare students with the necessary competencies to work in this field.

There are regular changes in the practice of neurology, given constant research developments in the domains of neurological assessment and treatment. Service provision is often characterised by limited resources, short and intermittent therapeutic input and a high therapist-client ratio. ${ }^{[3]}$ Therapists have alluded to the existence of possible gaps in the core knowledge and skills of the students they supervise in the clinical field. This highlighted the need for revision of the neurology curriculum at a university in Western Cape Province, SA. The current curriculum at this university is structured in such a way that students are taught physiology, anatomy and assessment of neurological components in their second year of study. The treatment of neurological conditions is taught in the classroom and in clinical settings throughout the third and final years of the academic programme.

The relevance and need for a curriculum to be responsive to the needs of the community have been highlighted by Frenk et al. ${ }^{[4]}$ These authors highlighted that the health professional of the 21st century requires additional tools to be a competent practitioner. They stressed that traditional training focused on the first two levels of learning, i.e. informative (learning of facts and skills) and formative (elements required to become a professional). They argue that students, however, also need to be exposed to transformative learning to ensure that the population's health needs are met, inequities are minimised and deficiencies in health systems are addressed.

Frenk et al.'s $\mathrm{s}^{[4]}$ theory on transformative learning was the conceptual framework underpinning this research. Within this framework, students need to become agents of change through their experiences of teaching and learning at a university. To ensure that learning is transformative, it is essential that the undergraduate occupational therapy neurology curriculum is relevant and responsive.

The relevance and responsiveness may therefore be facilitated through the use of a collaborative approach to curriculum design. ${ }^{[5-8]}$ Such an approach between clinicians and academic staff is essential to ensure that the knowledge, skills and attitudes that are taught, mirror what graduates need to provide, i.e. comprehensive, effective and efficient service within a given community. ${ }^{[7]}$

Studies using a collaborative approach to develop curricula have been conducted in various fields of occupational therapy, e.g. paediatrics, ${ }^{[9,10]}$ adult physical dysfunction ${ }^{[11]}$ and gerontology. ${ }^{[12]}$ A review of the literature has demonstrated that collaborative curriculum design in the field of neurology is limited and studies were either conducted in high-resource countries or focused on a single diagnosis in neurology, such as a cerebrovascular accident. ${ }^{[-7,73]}$

A study that explored the core skills and knowledge that an occupational therapy-specific undergraduate neurology curriculum should foster to enable graduates to provide interventions across all age groups and 
with regard to neurological conditions was conducted by McCluskey ${ }^{[6]}$ in Australia. This qualitative study included the views of occupational therapists on the core neurology content of a new occupational therapy course. Four main themes were identified that illustrated the knowledge and skills needed for practising in the field of neurology: (i) integrated foundation studies (neuroanatomy and neurophysiology) as prerequisites; (ii) the art of a thorough assessment; (iii) treatment approaches in neurology; and (iv) building confidence in clinical settings, as neurology was perceived as a difficult area of practice for students.

We report on one component of a larger collaborative study that focuses on the development of a relevant and responsive occupational therapy undergraduate neurology curriculum in the SA context. This larger study is two pronged and focuses on evidence-based practice and the views of a number of critical stakeholders, i.e. final-year occupational therapy students, and qualified occupational therapists and experts (i.e. academics and clinical educators). We also report on the views of qualified occupational therapists in terms of core knowledge, skills and attitudes needed by graduates, which should be included in the undergraduate occupational therapy curriculum, as well as factors that should be considered when revising the curriculum.

\section{Methods}

An explorative qualitative research study was conducted. ${ }^{[14]}$ The study population consisted of 10 occupational therapists working in the field of neurology in the Western Cape. Therapists who treat adults and/or children with neurological conditions were included.

Purposive sampling was used. The selection criteria included occupational therapists who were registered with the Health Professions Council of South Africa (HPCSA) and practising in the Western Cape. Therapists had to have worked in the field of neurology for at least 3 years, as according to Hodgetts et al. ${ }^{[8]}$ occupational therapists appeared to need 6 months - 2 years of clinical practice in a specific field to feel clinically competent.

Data were collected by means of a 60 -minute face-to-face semi-structured interview per participant. An interview guide was used, the questions were based on the literature and were guided by the objectives of the study. The interview guide consisted of two sections: (i) gathering of demographic information (personal and work characteristics) of the research participants; and (ii) gathering of qualitative data with 5 open-ended questions:

- What core knowledge would you suggest newly qualified therapists should have to work in the field of neurology?

- What core skills would you suggest newly qualified therapists should have to work in the field of neurology?

- What core attitudes would you suggest newly qualified therapists should have to work in the field of neurology?

- Are there any factors that should be considered when revising the neurology curriculum?

- In your opinion, what is the influence of resource constraints in practice and what should be considered when teaching students in the undergraduate curriculum?

Data saturation was reached after interviews had been conducted; ${ }^{[14]}$ the interviews were also audio recorded and transcribed verbatim. Burnard's ${ }^{[15]}$ framework for inductive data analysis was used, as well as a system of open coding with peer checking throughout. Similar codes were collapsed into categories; from these, overarching themes emerged.
Lincoln and Guba's ${ }^{[16]}$ model of trustworthiness for qualitative research was used to ensure rigour. Credibility was obtained by participants views, ensuring a good understanding of current neurology practice. Investigator triangulation was used to ensure dependability, whereby the research supervisor became the second investigator to analyse the data. Transferability was ensured by thick descriptions of procedures for data collection and analysis.

\section{Ethical approval}

Ethical approval was obtained from the Health Research Ethics Committee of Stellenbosch University (ref. no. N14/09/118). Participants were contacted telephonically to explain the purpose of the study and to determine their willingness to participate in the research. Written consent was obtained on the day of the interview before it commenced.

\section{Results}

The demographic profile of the participants is depicted in Table 1.

From the data analysis, four major themes emerged: (i) foundation knowledge and skills; (ii) intra- and interpersonal attitudes; (iii) suggestions to consider when revising a neurology curriculum; and (iv) resource constraints (Table 2).

\section{Discussion}

For the purpose of the discussion, knowledge and skills were combined, as the data did not differentiate between assessment knowledge and skills or treatment knowledge and skills. Participants stated that a solid foundation in generic knowledge may assist in students' understanding of the effect of underlying pathology on an individual's performance. These views are similar to those of occupational therapists in the Australian study. ${ }^{\left[{ }^{[6]}\right.}$

Assessment is an integral component of the occupational therapy process, which was reiterated by the participants. They highlighted that knowledge and skills of assessment need to extend beyond those of assessment for sensorimotor function, and encompass cognition, social functioning and context of the person. Assessment of the person in context provides for a more holistic understanding of the client and facilitates client-centred practice. Participants also advocated for a more functional approach to assessment, for which good observational and activity analysis skills are crucial.

Relevant treatment depends on core knowledge and skills of various treatment modalities. In addition, students need to develop clinical reasoning skills for an appropriate choice of treatment modality(ies) to address the needs of the patient. Participants emphasised the skill to integrate treatment modalities into functional activity. This integration is supported by the literature, which recognises the role of engagement and practice in functional tasks in neurological recovery from central nervous system dysfunction. ${ }^{[17-19]}$

Participants expressed the view that even though neurology-related knowledge and skills are essential, there are also key intrapersonal attitudes that need to be developed in graduates. This finding is different from that in other studies, ${ }^{[5,6]}$ where the focus of education and training was predominantly on knowledge and skills. According to Barnett, ${ }^{[20]}$ knowledge and skills are essential in developing competence, but training needs to extend to the fostering of graduates' attitudes, such as those that exhibit reflective and ethical practice. A common thread in this study and other 


\begin{tabular}{|c|c|c|c|c|c|}
\hline Participant & Gender & Clinical experience, years & Geographical work location & Work setting & Caseload \\
\hline 1 & Female & $>11$ & Rural & Acute-care hospital & Mixed $^{*}$ \\
\hline 2 & Male & $>11$ & Urban & $\begin{array}{l}\text { Outpatient and community-based } \\
\text { rehabilitation institute }\end{array}$ & Mixed $^{*}$ \\
\hline 3 & Female & $5-10$ & Urban & Acute-care hospital & Mixed $^{*}$ \\
\hline 4 & Female & $>11$ & Urban & $\begin{array}{l}\text { Acute-care hospital } \\
\text { Subacute or rehabilitation institute } \\
\text { Outpatient and community-based } \\
\text { rehabilitation institute } \\
\text { Old-age home }\end{array}$ & Mixed $^{*}$ \\
\hline 5 & Female & $>11$ & Urban/rural & Acute-care hospital & Mixed $^{*}$ \\
\hline 6 & Female & $>11$ & Urban & Special needs school & Mixed $^{*}$ \\
\hline 7 & Female & $5-10$ & Urban & $\begin{array}{l}\text { Outpatient and community-based } \\
\text { rehabilitation institute }\end{array}$ & Mixed $^{*}$ \\
\hline 8 & Female & $>11$ & Urban & $\begin{array}{l}\text { Acute-care hospital } \\
\text { Outpatient and community-based } \\
\text { rehabilitation institute }\end{array}$ & Neurological \\
\hline 9 & Female & $>11$ & Urban & Subacute or rehabilitation institute & Neurological \\
\hline 10 & Female & $3-4$ & Urban & Acute-care hospital & Neurological \\
\hline
\end{tabular}

studies was the need to improve students' confidence to work in the complex field of neurology. ${ }^{[5,6]}$ The findings also emphasise the importance of interpersonal attitudes that necessitate cognisance of the roles of other team members and the ability to communicate intervention plans to all involved. This was confirmed by Caldwell et al. ${ }^{[21]}$ where they highlighted the importance of effective communication and a good understanding of the roles of other team members as prerequisites for working as part of an effective team.

Resource constraints in practice settings and community contexts require that education and training equip students with innovative skills and the ability to identify ways of using existing resources to assist patients to attain their goals. Students further require training to enable them to advocate for patients to have access to resources embodied in the Bill of Rights of the SA Constitution.

A few suggestions emerged regarding factors to be considered when revising a neurology curriculum. Participants highlighted the importance of creating opportunities for more hands-on skills. They also alluded to the need for increased collaboration between clinicians and lecturers to narrow the gap between academic teaching and the practice setting. These findings concur with the perspectives of final-year occupational therapy students regarding suggestions that could be included in the revision of an undergraduate occupational neurology curriculum. ${ }^{[22]}$

\section{Study limitations}

Limitations of this study include the lack of variation in the sample in terms of the geographical work setting. The recruitment of additional participants who work in rural settings may have allowed increased insight into additional competencies that graduates require when working in such settings, as well as to inform further factors that should be considered when revising a neurology curriculum.

\section{Conclusions}

The study explored occupational therapists' perspectives of the knowledge, skills and attitudes that graduates need to work in the field of neurology. Findings reflect that there are various resource constraints and subsequent changes in the clinical platform in the Western Cape that have a direct impact on the training of students. Findings further highlighted that to practise in the field of neurology, new graduates require core knowledge, skills (both neurology specific and generic) and attitudes that address the evolving needs of society and allow them to work within the constraints of the health and educational systems.

Educators involved in revising undergraduate occupational therapy neurology curricula are urged to consider that preparing new graduates for practice in the 21st century necessitates that education and training encompass:

- opportunities for interprofessional teamwork, which would facilitate an increased awareness of their own roles and those of other professions to deliver holistic care

- a focus on an integrated teaching approach to facilitate optimal integration between neurology-specific content and generic principles of occupational therapy practice

- a closer alignment between the outcomes of the undergraduate neurology curriculum and the core competencies that will enable graduates to be competent practitioners

- the inclusion of evidence-based practice in teaching in conjunction with nurturing students' critical appraisal skills to ensure that they are able to select interventions that are most relevant and responsive to their patients' needs and contexts

- emphasis on a functional approach to assessment and treatment

- opportunities for students to cultivate their innovative skills so that they are able to work with the existing resources that are readily available within their patients' contexts. 
Table 2. Themes: Foundation knowledge and skills, intra- and interpersonal attitudes, suggestions to consider when revising a neurology curriculum and resource constraints

\begin{tabular}{ll}
\hline Theme & Category \\
\hline Foundation knowledge and skills & Foundational generic knowledge \\
This encompasses the core generic & $\begin{array}{l}\text { Participants shared the opinion that } \\
\text { knowledge of neuroanatomy, }\end{array}$ \\
physiology and pathology, including & newly qualified therapists to have a good \\
core knowledge pertaining to & understanding of neurological conditions in \\
occupational therapy-specific & terms of the clinical picture, aetiology and \\
neurological assessment and & prognostic factors \\
treatment & Neurological assessment \\
& The scope of the neurological assessment \\
& should cover a broad spectrum, ranging over \\
& assessing and interpreting components of the \\
postural response mechanisms, cognition, \\
perception, standardised testing and functions
\end{tabular}

Quotation

'... so long as they have a good knowledge of how hemiplegia presents ... then they should also have an understanding of what is muscular dystrophy, what is multiple sclerosis, Parkinson's disease, Guillain-Barré ... one really needs to have a good understanding of the symptoms ... a good knowledge of the pathology... and how that leads to the type of picture that the client presents.' (Participant 9)

'The core skills that they should have ... is a good grasp of assessment, and I'm talking of neurological assessments and physical assessments ... also cognitive assessments ... and psychological ... I would say social assessment of their circumstances ... ? (Participant 9)

'... some input on home visits, assessment in the home, assessment of ergonomics, assessment of your ... type of assistive devices ... . (Participant 2)

'It doesn't help that you can test but not understand the interpretation of what you have ... because you must know what to do with the information.' (Participant 5)

Neurological treatment

Treatment includes knowledge and skills of therapeutic modalities, activity analysis, applying a functional approach, selecting appropriate assistive devices and educating patients and their carers
Intra- and interpersonal attitudes This alludes to the importance of personal and interpersonal characteristics that are necessary to work in the field of neurology
Personal attitudes

Several attitudes were indicated as important for working in the diverse field of neurology, i.e. honesty, compassion, empathy, confidence and being non-judgemental

Interpersonal attitudes

These should be fostered during education and training to equip graduates to work with other team members and patients, their family and/or carers, including the ability to build good interpersonal relationships, be adaptable when working with different personality types, different developmental stages and different levels of education
'So you learn about weight bearing and tapping and all of those things ... you get the words and maybe the definition and you get shown how to do it on a healthy person, but, it doesn't necessarily mean that the student then has the ability to decide what of this is important for the specific patient ... that's why I think knowledge is not necessarily the problem, but the application is.' (Participant 1) 'So they get so much into the preparation and NDT [neurodevelopmental treatment] and stuff, which they don't actually translate into functional activity. When I'm talking about functional activity, I'm not talking about something the student or the OT [occupational therapist] thinks will be nice. It's what the client believes in and finds meaning for and what is relevant specific to them.' (Participant 9)

'Activity analysis ... and good observational skills, the students take an activity and think it's a nice activity, but this isn't correct thinking because they need to look at what the child's functional problem is, what you want to improve. Then you have to go and look for an activity that contains those components or whatever you want to enhance.' (Participant 6)

'Attitudes, one has to be honest with people as well, it's not always easy to deal with people who are unrealistic about their expectations and their recovery so you have to be willing to make time to help people go through that process of gaining insight, accepting the disability, accepting the loss and the change.' (Participant 2) 'You mustn't be scared to touch a patient ... you must just have a bit of self-confidence that you have already felt it ... ' (Participant 7) '... it's almost I would say $85 \%$ of the time you have both people; the carer and the patient ... and not to maybe forget about the carer treat the carer as well. So be mindful who is around this individual.' (Participant 8)

'I think there has to be a clear understanding of all the different disciplines' roles to be able to work in a team. (Participant 2) 
Table 2. (continued) Themes: Foundation knowledge and skills, intra- and interpersonal attitudes, suggestions to consider when revising a neurology curriculum and resource constraints

\begin{tabular}{|c|c|c|}
\hline Theme & Category & Quotation \\
\hline \multirow{12}{*}{$\begin{array}{l}\text { Suggestions to consider when revising } \\
\text { a neurology curriculum } \\
\text { This reflects possible suggestions on } \\
\text { the scope of content and instructional } \\
\text { methods to optimise integration } \\
\text { between theory and practice }\end{array}$} & Integration and application of practical skills & '... you cannot get insight into the patient and the treatment \\
\hline & The majority of participants stated that & techniques if you are not seeing them demonstrated, if you are not \\
\hline & students require the opportunity to practise & getting a little bit of practice; practice on a fellow student is not \\
\hline & more hands-on skills to apply what has been & always appropriate. You cannot get a sense of what the muscle tone is \\
\hline & learnt in the classroom & like... ? (Participant 2) \\
\hline & & $\begin{array}{l}\text { 'The ideal, I would say, is that you are shown, but then to physically } \\
\text { feel it for yourself.' (Participant 5) }\end{array}$ \\
\hline & Collaborative teaching approach & 'External people, the people who work in the field and ... \\
\hline & This should involve experienced lecturers, & have a passion for it, that have worked with students, I think \\
\hline & clinicians and experts in neurology from other & they must be contacted ... there aren't a lot of people who are \\
\hline & disciplines & NDT [neurodevelopmental treatment] trainers ... but there are \\
\hline & & physiotherapists and I don't think people should be reluctant to use \\
\hline & & them.' (Participant 1) \\
\hline \multirow{11}{*}{$\begin{array}{l}\text { Resource constraints } \\
\text { This encompasses the limited/ } \\
\text { unavailable resources in different } \\
\text { practice settings or contexts, which } \\
\text { impact on student education and } \\
\text { training }\end{array}$} & Practice settings & 'Obviously we have big workloads ... I can't watch my students do \\
\hline & These are under-resourced in terms of staff, & their sessions because I actually don't have time ... if we're lucky \\
\hline & resulting in a high workload, which causes & once a week, or once every second week, I get to do that, and then \\
\hline & constraints in terms of time available to teach & I'm basically not seeing my patients that I should see. So it's time that \\
\hline & and support students & is the biggest resource constraint.' (Participant 3 ) \\
\hline & Community context & '... a safe environment, money to get access to things they need, the \\
\hline & There are a number of resource constraints in & resources to get down the stairs from a fourth-floor flat, because \\
\hline & the communities where patients live (i.e. lack & it's human resources, because they need family and strong people \\
\hline & of social support, economic and accessible & to help them get down the stairs, they need access to resources like \\
\hline & community facilities), which have an influence & libraries and sport facilities in the community; those are not there, so \\
\hline & on patients' goal setting & \\
\hline
\end{tabular}

\section{Declaration. None.}

Acknowledgements. We acknowledge the participants and the Honours Research Group (2014), Division of Occupational Therapy, Department of Health and Rehabilitation Sciences, Faculty of Medicine and Health Sciences, Stellenbosch University: Alett-Marie Burger, Arauna van der Merwe, Esmaré Theron, Helena Langenhoven, Jessica Ramsay and Simoné van Tonder.

Author contributions. Both authors conceptualised the idea for the research. LJ-NK supervised the data collection. Both authors were involved in the analysis of the data and contributed to the write-up of this article.

Funding. Fund for Innovation Research Learning and Teaching (FIRLT).

Conflicts of interest. None.

1. South African Health Review. 2017. Durban: Health Systems Trust, 2017. http:// www.hst.org.za/media/Pages/HST South-African-Health-Review-2017 aspx (accessed 22 November 2018).

2. World Federation of Occupational Therapists. Definition and function of occupational therapy. 2017. http://www. traffic.libsyn.com;FOT_Definitions_2017_updated_June_2017aspx (accessed 11 April 2017).

3. Hassan S, Visagie S, Mji G. The achievement of community integration and productive activity outcomes by CVA survivors in the Western Cape Metro Health District. S Afr J Occ Ther 2012;42(1):11-15. https://doi org/10.4102\%2Fsajp.v67i2.39

4. Frenk J, Chen L, Bhutta Z, et al. Health professionals for a new century: Transforming education to strengthen health systems in an interdependent world. Lancet 2010;376(9756):1923-1958. https://doi.org/10.1016/S01406736(10)61854-5

5. Freeme J, Casteleijn D. A proposal for an undergraduate stroke rehabilitation curriculum appropriate for South Africa. S Afr J Occ Ther 2014;44(1):68-74.

6. McCluskey A. Collaborative curriculum development: Clinicians' views on the neurology content of a new occupational therapy course. Austr Occ Ther J 2000;47(1):1-10. https://doi:org/10.1046/j.1440-1630.2000.00200.x 7. Hanekom SD, Unger M, Cilliers F. Deriving criteria by which to determine core curriculum content: A high engagement process. Afr J Health Professions Educ 2014;6(2):181-184. https://doi.org/10.7196\%2Faihpe.496
8. Hodgetts S, Hollis V, Triska O, Dennis S, Madill H, Taylor E. Occupational therapy students' and graduates satisfaction with professional education and preparedness for practice. Can J Occ Ther 2007;74(3):148-160. https:/ doi.org/10.1177/000841740707400303

9. Dewire A, White D, Kanny E, Glass R. Education and training of occupational therapists for neonatal intensive care units. Am J Occ Ther 1996;50:486-503. https://doi.org/10.5014/ajot.50.7.486

10. Brown GT, Brown A, Roever C. Paediatric occupational therapy university programme curricula in the United Kingdom. Br J Occ Ther 2005;68(10):457-466. https://doi.org/10.1177/030802260506801004

11. Nelson CE, Cash SH, Bauer DF. Adult physical dysfunction content in professional curricula. Am J Occ The Nelson CE, Cash SH, Bauer DF. Adult physical dysfunction

12. Strasburg DM, Gingher MC. A review of entry level education in gerontology. Am J Occ Ther 1986;40:557-560. https://doi.org/10.5014/ajot.40.8.557

13. Schriner M, Thome J. Rehabilitation of the upper extremity after stroke: Current practice as a guide for curriculum. Open J Occ Ther 2014;2(1):1-14. https://doi.org/10.15453/2168-6408.1056

14. Merriam SB, Tisdell E. Qualitative Research. A Guide for Design and Implementation. San Francisco: Wiley and Sons, 2016.

15. Burnard P. A method of analysing interview transcripts in qualitative research. Nurse Educ Today 1991;11(6):461-466. https://doi.org/10.1016/0260-6917(91)90009-y

16. Lincoln YS, Guba EG. Paradigmatic controversies, contradictions and emerging confluences. In: Denzin NK, Lincoln YS, eds. The Sage Handbook of Qualitative Research. 4th ed. Thousand Oaks, CA: Sage Publications, 2011:97-128. 17. Dobkin B. Activity-dependent learning contributes to motor recovery. Ann Neurol 1998;44:158-160. https://doi. org $/ 10.1002 /$ ana.410440204

18. Carr JH, Shepherd R. Neurological Rehabilitation: Optimizing Motor Performance. Oxford: Butterworth-Heinemann 2010.

19. Thielman GT, Dean CM, Gentile AM. Rehabilitation of reaching after stroke: Task centred training vs progressive resistive exercise. Arch Phys Med Rehab 2004:85:1613-1618. https://doi.org/10.1016/.apmr.2004.01.028

20. Barnett R. The limits of competence: Knowledge, higher education and society. In: Hagerdorn R. Tools for Practice in Occupational Therapy. A Structured Approach to Core Skills and Processes. London: Harcourt, 2000:49-56. 21. Caldwell K, Atwal A, Copp G, Brett-Richards M, Coleman K. Preparing for practice: How well are practitioner prepared for teamwork. Br J Nurs 2006;15(22):1250-1254. https://doi.org/10.12968/bjon.2006.15.22.22565

22. Jacobs-Nzuzi Khuabi L, Bester J, Gatley-Dewing K, et al. Occupational therapy students' perspectives on the core competencies of graduates to practise in the field of neurology. Afr J Health Professions Educ 2017;9(1):39-43. https://doi.org/10.7196/AJHPE.2017.v9i1.722

Accepted 5 September 2019. 